\title{
Sophia de Mello Breyner Andresen e sua mitologia pessoal
}

\section{Sophia de Mello Breyner Andresen and her personal mythology}

\author{
Maria da Conceição Oliveira Guimarães \\ Professora Pesquisadora Independente, Natal, Rio Grande do Norte / Brasil \\ mcoguimaraes@gmail.com
}

Resumo: O propósito deste artigo é demonstrar que existe na poesia sophiana uma mitologia pessoal suportada por um olhar arguto e verticalizado sobre as coisas reais vistas e por uma palavra de compromisso ético. A pesquisa sobre esses dois pontos, olhar e palavra, foi conduzida pelos depoimentos de amigos e familiares e pelos seus próprios textos que demonstram o seu olhar particularizado sobre o mundo que a rodeia. Constata-se, ao final, que o olhar arguto e a palavra sacralizada por uma ética são os pilares de sua mitologia pessoal.

Palavras-chave: Sophia de Mello Breyner Andresen; poesia portuguesa contemporânea; Grécia; mito.

Abstract: The purpose of this article is to demonstrate that in Sophia Andresen's poetry there is a personal mythology supported by a sharp and deep look about the real things and by a poetic word of ethical commitment. The research on these two points, the look and the poetical word, was conducted by the testimonies of friends and family and her own texts have demonstrated her particularized view of the world. In the end, it is observed that the sharp look and the sacralized word by an ethic are the pillars of her personal mythology.

Keywords: Sophia de Mello Breyner Andresen; Portuguese contemporary poetry; Greece; myth.

Data de submissão: 30 de agosto de 2018

Data de aprovação: 8 de janeiro de 2019 


\section{A ideia de Grécia}

A recepção da cultura clássica grega na poesia de Sophia de Mello Breyner Andresen é um dado incontestável. Sua arte poética, ora revela um olhar devotado à exuberante geografia grega, bem como à sua arquitetura, inspirada nos estilos jônicos, dóricos e coríntios; ora reflete o passado mítico e seus deuses tutelares e, além disso, referencia poetas trágicos de sua predileção sem jamais se afastar do sentimento de pertença ao mundo real e concreto. Por conseguinte, é da derivação do patrimônio cultural grego que resultam suas recriações poéticas. Esse processo é singular porque é dotado de um método particularmente sophiano, característica pela qual se consolida sua mitologia pessoal.

Reconhecer a influência grega na poesia da autora não é somente um assunto de mera visão crítica, mas significa, sobretudo, anuir à tese defendida pela própria poetisa. Em uma entrevista ao jornalista António Guerreiro (Expresso, 15 jul. 1990, p. 54-57) Sophia ratifica essa filiação poética ao mundo grego: "Homero é, para mim, a referência matriz [...] Mas a minha maior atração pela arte grega foi sempre uma atração vital, que teve sempre muito a ver com a vida concreta e com a minha presença no mundo. E o contrário da evasão." O diálogo desenvolvido com o jornalista do Expresso exterioriza o veemente desejo de seguir o poeta épico grego como um modelo elevado de poesia. Não só os seus textos poéticos confessam essa filiação ao mundo grego, como também é fato que em momentos singulares de sua vida social Sophia tem admitido que a Grécia e seus mitos influenciaram seu modo de estar na vida e, por conseguinte, a sua criação poética. Em abril-maio de 1964, Sophia escreve a Jorge de Sena e lhe fala da Grécia e de sua arte como elemento vital e constituidor de uma força que parece unificar todo o seu ser.

Não tento descrever-lhe a Grécia nem tento dizer-lhe o que foi ali a minha total felicidade. Foi como se eu me despedisse de todos os meus desencontros, todas as minhas feridas e acordasse no primeiro dia da criação num lugar desde sempre pressentido. Sobre a Grécia só o Homero me tinha dito a verdade: mas não toda. (ANDRESEN, 2006, p. 65)

É sobre o efeito das emoções causadas pelo mundo grego que Sophia escreve "Acaia", primeiro poema da V divisão intitulada "Mediterrâneo" do livro Geografia (ANDRESEN, 1967). Nesse poema há 
uma transcendência do passado mítico glorioso de Acaia, cidade grega, ${ }^{1}$ bem como um reconhecimento de sua imperiosa grandeza que modifica corpo e mente. Composto por apenas um dístico, o poema causa no leitor a certeza da aliança indestrutível entre a cultura grega e o modo peculiar da poetisa ver e sentir a vida:

Aqui despi meu vestido de exílio

E sacudi de meus passos a poeira do desencontro (ANDRESEN, 2010, p. 497).

Observa-se, portanto, que por trás do encantamento nutrido pelo patrimônio cultural grego, tão amiúde entoado, existe uma indiscutível mitologia pessoal, mitologia essa que tem como princípio de sustentação um olhar arguto que mapeia e fixa as imagens alcançadas.

\section{Olhar arguto e perscrutador}

Sophia olha ao seu redor para extrair o invisível do visível, ou mesmo para refundar ou refinar poeticamente o já descoberto. É nesse sentido que seu olhar corporifica um dos elementos fundadores de sua mitologia pessoal. O olhar que a poetisa lança ao patrimônio cultural grego não expressa um simples espelhamento sobre as coisas reais vistas, uma vez que o espelhamento revela apenas o que está à tona. Trata-se de uma visão restabelecedora do passado e depuradora do presente. A sua análise óptica sobre a realidade física grega vai da superfície ao fundo da pedra que compõe a escultura e a arquitetura secular. Ao posar seus olhos sobre o mundo físico grego, a poetisa examina a sua raiz histórica, transmitindo ao leitor um legado de esplendor e de glória.

O poema-prosa "Epidauro", do livro Geografia (1967), testemunha essa herança. Nele, o sujeito poético explicita o reconhecimento do quanto a natureza em Epidauro, cidade antiga grega, é exuberante e o quanto a manifestação desse universo é positiva para a conquista da liberdade e da justiça. No país da imanência do real, a revelação de sua claridade é singular, é o que parece assegurar o sujeito poético:

\footnotetext{
${ }^{1}$ Existiram duas Acaias: uma é a região na parte centro-norte do Peloponeso que formou a confederação conhecida como Liga Acaia e foi influente durante os séculos III e II a.C. No século VI a. C, Homero descreveu as proezas dos aqueus na Guerra de Troia nesta mesma Acaia. (Ilíada, Canto II, vs. 110-130). Já a outra é uma província do Império Romano. Cf. Machado (2003).
} 
Eis o país do exterior onde cada coisa é:

trazida à luz

trazida à liberdade da luz

trazida ao espanto da luz

(ANDRESEN, 2010, p. 501).

Depois de se despir das impurezas do tempo, como faz supor o poema "Acaia", o sujeito poético, extasiado pela abundante natureza, oferta-se liturgicamente a essa Epidauro, plena de claridade:

Eis-me aqui vestida de sol e de silêncio.

(ANDRESEN, 2010, p. 501).

O poema é concluído por um vaticínio de liberdade abrigado pela placidez e pela claridade, sugerindo que somente a luz de Epidauro é capaz de libertar aqueles que se sentem prisioneiros das agruras da vida:

Só poderás ser liberta aqui na manhã d'Epidauro. Onde o ar toca o teu rosto para te reconhecer e a doçura da luz te parece imortal. A tua voz subirá sozinha as escadas de pedra pálida. E ao teu encontro regressará a teoria ordenada das sílabas - portadoras limpas da serenidade. (ANDRESEN, 2010, p. 501)

Não somente Epidauro, a cidade grega, é a causadora de seu espanto e êxtase, mas o teatro de mesmo nome, construído na primeira metade do século IV a. C., exerce igualmente rica e intensa força em sua poesia. Além de ser uma fonte histórica, esse teatro exprime a epifania cênica das tragédias gregas que ainda hoje se configuram em modelos trágicos recebidos pelo mundo ocidental. Por conseguinte, Epidauro, o teatro, também significa a nítida consciência da poesia que na autora reverberava. A "Arte poética V", texto lido na Sorbonne em dezembro de 1988 por ocasião do encontro intitulado Les Belles Étrangères, ratifica a afirmação:

Um dia em Epidauro - aproveitando o sossego deixado pelo horário do almoço dos turistas - coloquei-me no centro do teatro e disse em voz alta o princípio de um poema. E ouvi, no instante seguinte, lá no alto, a minha própria voz, livre, desligada de mim. Tempos depois, escrevi estes três versos: ${ }^{2}$

\footnotetext{
${ }^{2} \mathrm{O}$ texto ao qual Sophia se refere em seu discurso chama-se "Epidauro 62" e se encontra na primeira parte do livro Ilhas (1989), intitulada "Poemas reencontrados".
} 
A voz sobe os últimos degraus

Oiço a palavra alada e impessoal

Que reconheço por não ser já minha.

(ANDRESEN, 2010, p. 848)

O magnetismo do olhar da autora sobre a arte e a cultura grega realiza uma síntese entre o espaço originário da proto-história grega e o espaço da presença identitária. O tema desenvolvido no poema "No Golfo de Corinto" do livro Geografia (1967) legitima essa conexão. Sua empatia pela terra e pelos deuses persuade o leitor de que há um desejo sempiterno realizado, cujos deuses e terra são um todo indivisível, atesta a poetisa,

No golfo de Corinto

A respiração dos deuses é visível:

É um arco um halo uma nuvem

Em redor das montanhas e das ilhas

Como um céu mais intenso e deslumbrado

(ANDRESEN, 2010, p. 498).

A presença das ruínas de um passado milenar se junta ao real concreto para formar uma imagem aureolar sancionadora da beleza daquele sagrado golfo em Corinto. O hino aos deuses e à terra está implícito na canção entoada pelo sujeito poético:

E também o cheiro dos deuses invade as estradas

É um cheiro a resina a mel e a fruta

Onde se desenham grandes corpos lisos e brilhantes

Sem dor sem suor sem pranto

Sem a menor ruga de tempo

(ANDRESEN, 2010, p. 498) dos homens:

O final do poema gesta o entrelaçamento da terra, dos deuses e E uma luz cor de amora no poente se espalha

É o sangue dos deuses imortal e secreto

Que se une ao nosso sangue e com ele batalha

(ANDRESEN, 2010, p. 498). 
Outro exemplo do olhar de imbricação poética entre a geografia grega e seus deuses assenta-se perfeitamente no poema "Sunion" (Geografia, 1967).

Na nudez da luz (cujo exterior é o interior)

Na nudez do vento (que a si próprio se rodeia)

Na nudez marinha (duplicada pelo sal)

Uma a uma são ditas as colunas de Sunion

(ANDRESEN, 2010, p. 499)

Nesse poema, a plasticidade geográfica localiza o templo Sunion erigido ao deus grego do mar, Poseidon, sobre o desfiladeiro no cabo Sunion, extremo oriental da Ática. Sunion, o lugar, açoitado pelos ventos e inundado de sol, é majestosamente representado pelos três primeiros versos. O último verso caracteriza Sunion, o templo, onde se perfilam colunas dóricas de seis metros de altura, infinitamente brancas sob o azul luminoso do céu no mediterrâneo.

A recepção dos aspectos das lendas na poesia sophiana não significa um processo banal de criação. Esse processo criativo requer um conhecimento iniciático histórico-mítico que, como um fio de Ariadne, conduzirá o leitor pelo labirinto que não é aquele construído por Dédalo, mas aquele que a poetisa projetou em sua poética. Já o conhecimento prévio da matriz protomítica pelo leitor, permitir-lhe-á a recuperação da informação lendária sobre Poseidon, o deus do mar, sem a necessidade do poema mencioná-lo.

A marcante singularidade da poesia sophiana em relação à paisagem grega e seus deuses pressupõe também uma excepcional verticalidade de seu olhar sobre real. Os testemunhos de pessoas amigas e parentes legitimam essa invulgar capacidade poética. Algumas dessas declarações são imprescindíveis para a compreensão da hipótese que aqui se pretende provar. Em 2011, por ocasião do Colóquio Internacional sobre Sophia, na Calouste Gulbenkian, Armando da Silva Carvalho, advogado, poeta e amigo da Sophia fez-lhe uma arrebatadora homenagem. Desdobrando-se em uma emocionada "confissão de inveja" sobre o já propalado olhar/sentir de Sophia, declarou:

Tenho inveja do mar de Sophia, que eu nunca soube ver no meu, que também o tive desde a infância. Tenho inveja da Grécia de Sophia porque nunca vi as pedras de Atenas com os seus olhos. 
Tenho inveja dessa maçã, ${ }^{3}$ enorme, vermelha que ela viu em nova no quarto frente ao mar... (COUTINHO, 2011, p. 16).

Em conformidade com as declarações de amigos e poetas sobre o distinto e atento olhar de Sophia, o jornalista Miguel Sousa Tavares, filho da autora, revela que Sophia também era uma viajante sui generis, justamente em virtude de seu olhar cheio de perspicácia. Em um artigo escrito pós-morte da autora, Tavares declara que ela lhe ensinou a busca de um crescimento pessoal através de um olhar atento de viajante.

[...] aprendi a viajar com minha mãe, graças a uma simples frase dela, dita no momento exato e no local exato: na Piazza Navona, em Roma, cerca das seis horas da tarde e depois de uma hora de chás, cigarros e contemplação silenciosa da geometria perfeita da praça. Sentindo a minha impaciência - a impaciência de quem estava em Roma pela primeira vez e tudo queria ver, sem detença -, ela disse: 'Miguel, viajar é olhar'. (TAVARES, 2011, p. 127)

A essa maneira íntima de ver as coisas e fundi-las ao ritmo do mundo e ao ritmo de sua alma, o jornalista Francisco Sousa Tavares, marido e primeiro crítico de sua poesia, lança a seu crédito um particular e excepcional caráter ótico-poético. No posfácio da antologia Mar: Poesia, Tavares (2001, p. 74) menciona que "Sophia Andresen escreve o seu mundo e o mundo que lhe entrou pelos olhos extasiados, tudo fundido naquele ritmo de música e dança, de harmonia clara que é para ela uma exigência e um estilo." (grifo meu).

O universo sensível de sua observação é uma forma já tipificada por familiares, amigos e críticos literários, decerto torna-se mais evidente quando ela própria confere-lhe significância e literariedade poética. Em "As grutas", poema-prosa do Livro Sexto (1962), a poetisa expressa o deslumbramento contido nas imagens construídas em momentos de puro encanto visual. Ao pousar seu rosto na superfície da água do mar para ver o que havia em suas profundezas sente-se perfeitamente integrada à natureza e àquele ambiente. $\mathrm{O}$ instante real e poético ao mesmo tempo é confidenciado pela autora, "As imagens atravessam os meus olhos e

${ }^{3}$ Cf. “Arte poética III", in Obra Poética, 2010, p. 309. 
caminham para além de mim. Talvez eu vá ficando igual à almadilha ${ }^{4} \mathrm{da}$ qual os pescadores dizem ser apenas água." (ANDRESEN, 2010, p. 397)

No mesmo poema, Sophia descreve o medo-pânico que sente naquele átimo em que visualiza a complexidade das profundezas do mar e, por extensão, a heterogeneidade de seu ser: "Eis o mar e a luz vistos por dentro. Terror de penetrar na habitação secreta da beleza, terror de ver o que nem em sonhos eu ousara ver, terror de olhar de frente as imagens mais interiores a mim do que o meu próprio pensamento." (ANDRESEN, 2010, p. 397)

Os seus mapas óticos fundem no leitor o encanto do mistério iniciático da vida. Os cenários plenos de clareza de ideias e beleza transformam-se em palavra pura, criadora de poesia.

\section{A inteireza da palavra e as musas}

Ao meditar sobre as imagens preexistentes, sejam os modelos gregos eternos e perfeitos e seus mitos de cariz religioso ou ainda o real caótico circundante, Sophia faz ressurgir a palavra como uma forma mágica em sua plenitude e inteireza, perpetuando-a ao sabor do tempo.

A poetisa é artífice de uma linguagem sóbria, despida de excessos de palavras, virtude já percebida pelo crítico Carlos Ceia, quando refere que na poesia sophiana "nenhuma palavra está a mais, cada verso só por si pode ser um poema". (CEIA, 1994, p. 183-187). Essa característica da poesia sophiana mencionada por Carlos Ceia é referendada por outros críticos, a exemplo do que afirma o jornalista António Guerreiro no semanário Expresso (1994): “Os seus versos são feitos de palavras justas e verdadeiras - e isto significa que foram expurgados de todas as inflexões retóricas e não há neles espaços para o decorativo."

Os testemunhos de Guerreiro e de Ceia, acima mencionados, adquirem robustez e força quando a sua própria poesia é um legado de respeito para com a palavra. Nesse aspecto, considera-se que a palavra é um dos esteios que suporta a estrutura da mitologia pessoal sophiana.

Note-se, para tanto, que em 1974, há poucos meses decorridos da "Revolução dos Cravos", Sophia escreveu o poema "Com fúria e com

\footnotetext{
${ }^{4}$ Sophia cria o vocábulo "almadilha", licença poética permitida a todo artista da palavra. Supõe-se que essa expressão pode ter sido composta a partir da linguagem informal dos pescadores e de seu imaginário nauta, apontando para algo dissimulado como uma armadilha do fantástico mundo marinho.
} 
raiva", que foi publicado no livro $O$ nome das coisas (1977). Os versos desse canto de denúncia revelam que a palavra tem sido, reiteradas vezes, conspurcada pelos homens e, no caso específico, pelos dirigentes políticos portugueses. Por essa razão, a poetisa insurge-se contra aquele que a mutila, que a macula. A repulsa e o asco apontam para a desonra daquele que age de forma oportunista e ambiciosa com a palavra.

Com fúria e raiva acuso o demagogo

E o seu capitalismo das palavras

Pois é preciso saber que a palavra é sagrada

Que de longe muito longe um povo a trouxe

E nela pôs a sua alma confiada

De longe muito longe desde o início

O homem soube de si pela palavra

E nomeou a pedra a flor a água

E tudo emergiu porque ele disse

Com fúria e raiva acuso o demagogo

Que se promove à sombra da palavra

E da palavra faz poder e jogo

E transforma as palavras em moeda

Como se fez com o trigo e com a terra

Junho de 1974

(ANDRESEN, 2010, p. 621)

Naquela altura, Sophia pressente que a palavra comprometida por ocasião da Revolução dos Cravos transformou-se em quimera na boca do demagogo. Mesmo sendo um poema datado porque foi escrito dois meses depois daquela revolução, é legítimo afirmar que nele há, além da denúncia sobre a depreciação da palavra, um pedido de respeito pela palavra deliberada ontem, mas também pela palavra articulada hoje e aquela que será motivada sempre. As nítidas referências ao sentimentopânico que reside no desrespeito à palavra proferida reverberam no poema. Em um mundo desordenado, a palavra acordada e comprometida, ou seja, a palavra pura tem o condão de se tornar um bem inalienável e não a sua negação, parece sugerir o sujeito poético.

A maioria dos poetas, incluindo-se nesse rol Sophia, não descura da reverência à palavra articulada porque entendem que a palavra foi o 
elemento sagrado da exemplaridade desde tempos imemoráveis. Os povos ágrafos são o exemplo básico dessa afirmação uma vez que cumpriam terminantemente o lógos (palavra, linguagem) acordado. O poder dos ensinamentos ancestrais orais e os preceitos escritos na atualidade são conceitos indissociáveis e intransponíveis na poesia da autora. Por essa razão é que no poema "A palavra", de O nome das coisas (1977), a poetisa retoma uma máxima do filósofo pré-socrático Heráclito, para quem o lógos é um conjunto harmônico de leis que comanda o universo, e um provérbio dos Malinkés para realçar a necessidade de apreço à palavra. Para demonstrar a inevitabilidade do poder da palavra e de sua valia em qualquer lugar e época, a poetisa une o mundo grego de Heráclito, filósofo do sec. VI a. C., à cultura Malinké, povos originários do oeste africano que foi um dos impérios mais fortes na Idade Média.

Heraclito de Epheso diz:

"O pior de todos os males seria

A morte da palavra"

Diz o provérbio do Malinké:

"Um homem pode enganar-se em sua parte de alimento

Mas não pode

Enganar-se na sua parte da palavra"

(ANDRESEN, 2010, p. 632)

A palavra dada, segundo depreende-se desse poema, é portadora de um compromisso ético inabalável selado entre aquele que a profere e aquele que a aceita, como assim a interpreta Montaigne: "A palavra é a metade de quem a pronuncia, metade de quem a escuta". (Ensaios, 2001, livro III, Capítulo XIII). Em "A palavra" o sujeito poético expressa o entendimento comum entre os povos antigos no qual reside a crença de que a palavra proferida é flecha lançada, logo não há como apagar o que já foi dito. Sob o ponto de vista da associação histórica e temporal, é notável a significação de inteireza do lógos no poema "A palavra". História e tempo parecem ressignificar as possibilidades que a palavra concede ao homem para que nela se concretize sua ética pessoal.

A essência do efeito responsável da palavra também está contida no poema "Trípoli 76". Nele, antevê-se o fio condutor de um labirinto humano onde os caminhantes dos diversos mundos ali se cruzam e se descruzam, 
$[\ldots]$

Falando muitas e diversas línguas

Vêm de muitos e diversos ritos

E cultos e culturas e paragens.

(ANDRESEN, 2010, p. 653)

Nessa babel linguística e étnica, que o poema remete a Trípoli e a Leptis Magna, ${ }^{5}$ é que

O recitador entoa a palavra modulada

Rouca de deserto e sol e imensidão

Entoa a veemência nua da palavra

Fronteira de puro Deus e puro nada

(ANDRESEN, 2010, p. 653)

O alcance do poder da palavra na atualidade, seja poética ou prosaica, passa inevitavelmente por uma perspectiva religiosa, uma vez que se torna necessário revestir o lógos da atualidade de uma potência sagrada que, de algum modo, já lhe foi conferida pelos povos ancestrais.

Há na proto-história dos nautas gregos uma figura trágica, Medeia, que acumula um conjunto de qualidades essenciais ao seu poder mágico através da palavra motivada. Essa lenda foi reunida por Ovídio no século I a. C. em seu livro Metamorfoses, a partir do poema Argonáutica de Apolónio de Rodes, séc. III a. C., segundo algumas fontes míticas. Sophia apropria-se do material helenístico desenvolvido por Ovídio e transmuta-o no poema "Medeia", publicado em Dia do mar (1947), sem esquecer-se de informar ao leitor que é uma adaptação dos versos do poeta latino. Tanto no texto latino como no texto sophiano, o início do caminho trágico da princesa cólquida é traçado pela necessidade de execução dos poderes mágicos através do imperioso poder da palavra.

$\mathrm{Na}$ lenda mítica, essa maga insta seu imaginário consentâneo de acordo com os seus próprios interesses, entretanto a magia só acontece quando a palavra exerce o poder hierático de fletir as árvores e esfrangalhar os homens com sua ressonância. A palavra tornada magia realiza a ligação entre a invocação da maga e os deuses e, em consequência disso, a palavra funciona como um atributo de persuasão

\footnotetext{
${ }^{5}$ Referência implícita às rotas comerciais na antiguidade greco-romana que interligavam diversos povos ao longo do tempo da Europa à Ásia.
} 
indispensável a Medeia. Em um implícito jogo de cumplicidade com o leitor, Sophia demonstra que os efeitos mágicos exercidos por Medeia somente são possíveis através do poder encantatório da palavra, uma vez que a apropriação que Sophia faz do poema Metamorfoses ocorre no momento exato em que a feiticeira toma posse do dom que lhe é facultado pelos deuses, a palavra.

Três vezes roda, três vezes inunda

$\mathrm{Na}$ água da fonte os seus cabelos leves,

Três vezes grita, três vezes se curva

E diz: 'Noite fiel aos meus segredos,

Lua e astros que após o dia claro

Iluminais a sombra silenciosa,

Tripla Hecate que sempre me socorres

Guiando atenta o fio dos meus gestos,

Deuses dos bosques, deuses infernais

Que em mim penetre a vossa força, pois

Ajudada por vós posso fazer

Que os rios entre as margens espantadas

Voltem correndo até às suas fontes.

Posso espalhar a calma sobre os mares

Ou enchê-los de espuma e fundas ondas,

Posso chamar a mim os ventos, posso

Largá-los cavalgando nos espaços.

As palavras que digo e cada gesto

Que em redor de seu som no ar disponho

Torcem longíquas árvores e os homens

Despedaçam-se e morrem no seu eco.

Posso encher de tormento os animais,

Fazer que a terra cante, que as montanhas

Tremam e que floresçam os penedos.'

(ANDRESEN, 2010, p. 133) ${ }^{6}$

Reitera-se que, embora o poema registre todo o ritual utilizado pela feiticeira na realização do hermetismo pretendido, a conclusão

${ }^{6}$ Cf. a edição francesa da "Les Belles Lettres", 1985, Tomo II, livro VII, p. 35-36, vs. 190-207. 
do arrebatamento mágico somente é conseguida quando a palavra transforma-se em elemento vital do processo cabalístico de Medeia. Sophia trata a palavra em aspectos e objetivos distintos dos utilizados por Medeia uma vez que sua aspiração tem como meta a supremacia veneranda da palavra entre os homens. Retoma a tragédia Ática apenas para demonstrar que a palavra também é magia, pois retém em si um poder infalível em todas as instâncias da vida humana, pois é dicção, é canto e, sobretudo, é poder.

Os poetas que recorrem às musas, filhas diletas de Mnemósine, ilustre deusa da memória inscrita no Panteão grego, fazem-no com o propósito de compor um belo canto. A princípio, a relação dos poetas com Mnemósine representa o momento em que o imaginário do homem solidifica as circunstâncias coletivas sociais em relação ao sentimento do tempo e seu enigma. A seguir, as musas, suas filhas, são o princípio e a condição de inspiração do canto poético àqueles que apelam aos seus poderes. Diante dessas prerrogativas divinas, os poetas apropriam-se, sem reservas doutrinárias, da preciosa carga poética guardada por Mnemósine e concedida pelas musas para compor suas galerias de poemas sobre os sentimentos humanos, sejam eles belos ou aviltantes. Percebedores dos divinos artifícios das musas, os poetas invocam-nas, como o fez Hesíodo: "Comecemos por cantar as Musas Helicónidas." (HESÍODO, 2005, p. 39); Homero: "Dizei-me agora, ó Musas que no Olimpo tendes vossas moradas - pois sois deusas, estais presentes e todas as coisas sabeis, [...]" (HOMERO, 2005 Canto II, vs. 484-5).

Sophia, tal qual um demiurgo, investe-se do poder da palavra e evoca as divindades do divino Monte Hélicon como o faziam os aedos na Antiguidade e como o fazem ainda hoje os poetas modernos. Sobre a influência que as musas exercem em sua criação, há dois poemas significativos sobre pedidos de inspiração divina em dois livros distintos da poetisa. Um, é "Musa" do Livro sexto (1962) e o outro, também "Musa" do livro Dual (1972). No Livro sexto (1962), Sophia invoca diretamente as musas. A solicitação inflamada é um clamor de inadiável inspiração que remete às circunstâncias do tempo, pois é necessário que a força criadora dessas divindades concretize-se antes que Mnemósine perca-se nas trevas da história, arrastando consigo a memória. 
Musa ensina-me o canto

Venerável e antigo

O canto para todos

Por todos entendido

Musa ensina-me o canto

[...]

Pois o tempo me corta

O tempo me divide

O tempo me atravessa

E me separa viva

Do chão e da parede

Da casa primitiva

Musa ensina-me o canto

Venerável e antigo

Para prender o brilho

Dessa manhã polida

Que poisava na duna

Docemente os seus dedos

E caiava as paredes

Da casa limpa e branca

Musa ensina-me o canto

Que me corta a garganta.

(ANDRESEN, 2010, p. 390)

Já o "Musa" do livro Dual (1972) é um poema de escuta pelo poder da palavra, dom que a poetisa espera ser revelado através da temporalidade e da história, dando conta dos fenômenos humanos e dos atos que inauguram o mundo. Uma vez já feito o pedido, doravante a poetisa se põe à espera de que as musas lhe concedam o belo canto.

Aqui me sentei quieta

Com as mãos sobre os joelhos

Quieta muda secreta

Passiva como os espelhos 
Musa ensina-me o canto

Imanente e latente

Eu quero ouvir devagar

$\mathrm{O}$ teu súbito falar

Que me foge de repente.

(ANDRESEN, 2010, p. 571)

Tanto "Musa" do Livro sexto quanto "Musa" de Dual caracterizamse por reivindicações modelares do poder encantatório das filhas de Mnemósine, no entanto, no primeiro há um brado de urgência, já no segundo há uma espera, porém ambos fortalecem um dos pilares de sustentação da mitologia pessoal sophiana: a religiosidade da palavra poética. Além de trazerem consigo uma memória pluralista para com a contemporaneidade, a invocação às musas por Sophia recupera um sentido já sedimentado na psique da cultura ocidental no que diz respeito às criações e recriações poéticas.

\section{Poesia}

Muitos poetas registram em suas criações uma espécie de simbiose com o passado grego através do beneplácito de Mnemósine e suas filhas, por esse motivo, torna-se lugar comum afirmar-se que os poetas são conduzidos por essas divindades. Na poesia sophiana essa influência é visível além de ser por ela amplamente confirmada. Em "Arte poética IV”, Sophia admite que sua forma de construção poética é semelhante a de Fernando Pessoa, pois, segundo a poetisa, ambos conceberam sob a regência de um "poeta possesso", ou seja, aquele que se vale das musas em sua criação:

Fernando Pessoa dizia: 'Aconteceu-me um poema'. A minha maneira de escrever fundamental é muito próxima deste 'acontecer'. O poema aparece feito, emerge, dado (ou como se fosse dado). Como um ditado que eu escuto e noto. [...] Sei que o poema aparece, emerge e é escutado num equilíbrio especial da atenção, numa tensão especial da concentração. O meu esforço é para conseguir ouvir o "poema todo" e não apenas um fragmento. Para ouvir o "poema todo" é necessário que a atenção não se quebre ou atenue e que eu não intervenha. [...] Como, onde e por quem é feito esse poema que acontece, que aparece como já feito? A esse "como, onde e quem" os antigos chamavam Musa. 
[...] Deixar que o poema se diga por si, sem intervenção minha (ou sem intervenção que eu veja), como quem segue um ditado (que ora é mais nítido, ora mais confuso), é a minha maneira de escrever. (ANDRESEN, 2010, p. 844-847)

Se a influência divina sobre a criação poética sophiana é um dado insofismável, ela, por sua vez, também é um "poeta artífice", aquele que trabalha arduamente para desentranhar do material recebido pela ação daquelas divindades a beleza e a crueldade que o mundo encerra. Amparando-se nessa hipótese, entende-se que a recriação de poemas através dos textos clássicos, sobretudo da poesia trágica, mesmo que seja por inspiração divina, é seguramente o trabalho de um "poeta artífice" em virtude de o novo poema ser criado a partir daquele que lhe serviu de exemplo. Pela via do mito, a poetisa apropria-se dos textos clássicos e os retrabalha, dando-lhe cores e feições modernas. Sob esse aspecto, pode-se afirmar que ela é uma participante inconteste do banquete trágico oferecido por Eurípides, "o descobridor da alma num sentido completamente novo, o inquiridor do inquieto mundo dos sentimentos e das paixões humanas", como a ele se reporta, Jaeger, (JAEGER, 1995, p. 408).

$\mathrm{Na}$ tragédia Ifigénia em Áulide, o tragediógrafo trata o drama da princesa grega em diversos aspectos da vida cotidiana mítica. Através da função religiosa desvela a exigência de uma deusa irritada, Ártemis, que decreta o sacrifício da filha do anax, Agamêmnom, como prêmio pelo insulto a ela dirigido; aborda questões políticas como a crueza operada durante a cruzada pan-helênica - guerra de Troia - e exibe com requinte a tirania que atinge as mulheres gregas dentro daquele espaço. $\mathrm{O}$ texto euripidiano evidencia que no contexto do mundo antigo não cabia a nenhuma mulher uma morte gloriosa, como o destino reservara aos guerreiros, mesmo que ela fosse filha de um poderoso rei.

Na peça trágica, depois de descoberta a trama urdida por seu pai, Ifigênia toma consciência de que seus pedidos de clemência não causam comiseração nem à deusa nem ao seu genitor, portanto afasta-se de sentimentos execráveis de piedade e vai além de uma simples resignação. Sente que sua vida é demasiadamente pequena diante do esplendor da Grécia. A partir daí, nasce-lhe um orgulho exaltado motivado pela certeza do grande serviço que prestará ao seu país. Lúcida, Ifigênia rejeita o motivo medíocre da guerra por causa de uma mulher infiel - a bela Helena - e se junta ao motivo político, a grande cruzada pan-helênica. Seu sacrifício tornará possível a vitória dos gregos em Troia e, por 
conseguinte, enaltecerá o seu heroísmo, contradizendo o status quo de então. O diálogo desenvolvido entre Ifigênia, Clitemnestra, sua mãe, e o coro contempla tal decisão:

Ifigênia:

Não quero que vertas lágrimas.

e vós entoai um péan, ó jovens raparigas,

[...]

Conduzi-me que eu sou

a destruição de Ílion e dos Frígios.

$[\ldots]$

... criaste-me para ser a luz da Hélade,

e não me recuso a morrer.

[...]

$\mathrm{Oh}$ ! Oh!

Dia, senhor da luz,

e de Zeus esplendor, é outra

a vida e destino que irei viver.

Recebe o meu adeus, amada luz do dia!

(EURÍPIDES, 2008, p. 105-106)

A memória trágica, reminiscência submersa na proto-história e aflorada tanto pela épica homérica quanto pela tragédia de Eurípides, é retrabalhada pela moderna poesia sophiana. O poema "Ifigénia em Áulis", do livro Coral (1950), é uma reconstrução concebida a partir da alteração do curso dos acontecimentos operada por Eurípides em sua peça. Sophia apreende dos versos da tragédia aquilo que é vital, o registro perpétuo de uma ação que glorifica pátria e mulher. Ifigênia enfrentará deliberadamente a morte. Sua decisão repentina inverte os polos da vitória.

Ifigénia levada em sacrifício,

Entre os agudos gritos dos que a choram,

Serenamente caminha com a luz,

E o seu rosto voltado para o vento,

Como vitória à proa de um navio,

Intacto destrói todo o desastre.

(ANDRESEN, 2010, p. 218) 
O poema enaltece a crença nas lendas da casa micênica configuradas nessa personagem que crê na glória límpida e imortal. No cerne do conflito, enquanto seu pai prioriza kléos (a glória), e o mérito pela hybris, (a fúria guerreira), desprezando a philia (os afetos domésticos), ela decide-se pelos seus e pela pátria, em nome da philia. No entanto, o ser de philia transforma-se em um ser de kléos. Determinada, passa a ser orientada por uma rhesis (rotação) que lhe permite ofertar-se ao sacrifício voluntariamente em favor de sua glória e da sua casa real. Por esse motivo, segue altiva, "Entre os agudos dos que a choram", cujo pranto é representado pelo coro de anciãos e pela soldadesca aquartelada. "Serenamente caminha com a luz", brilho que é a própria essência de concepção do mundo grego. Esta jovem, que acaba de amadurecer pela dor, evoca o sentido ancestral do risco máximo de vida em nome de uma admiração coletiva eterna. A entrega frontal e majestosa, com o "seu rosto voltado para o vento", simboliza Éolo, o deus dos ventos, prêmio esperado pelos guerreiros. Doravante, ela é o próprio vento necessário aos gregos sitiados no Golfo de Áulide, simbolizando igualmente uma poderosa confirmação de sua honra e de sua glória. É também a alegoria da "Vitória de Samotrácia", personificação do triunfo. Perfila-se "como vitória à proa de um navio" e "... destrói todo o desastre" que até então parecia ser o destino do exército grego acantonado em Áulide. Embora Ifigênia seja a fatia de conquista da deusa, no entanto ela torna-se, sobretudo, a protagonista do seu destino.

Pelo olhar e pela palavra poética ética e justa é que se estabelece a mitologia pessoal de Sophia. Sob o manto dessa poética particularizada, Sophia assume a modéstia dos gênios e fala sobre a grandeza de um passado mítico-religioso para compreender o presente, pois como afirma, "Aquele que vê o espantoso esplendor do mundo é logicamente levado a ver o espantoso sofrimento do mundo." (ANDRESEN, 2010, p. 841). O seu olhar saúda na terra grega suas ruínas arquitetônicas e sua inigualável natureza. No Museion (morada das musas), vai buscar a inspiração para desentranhar as sutilezas de seu majestoso cantar. O desfile das personagens míticas sustenta-se pela palavra poética transformadora, o que torna o leitor um ser de cultura universal e ecumênica ao prantear o destino inexorável de uma jovem entregue por seu pai para imolação a uma deusa abespinhada por ter tido seu poder divino desdenhado por um mortal. Olhar e palavra, cerne da mitologia pessoal de Sophia, revolvem os húmus dos sentimentos soterrados sob a arqueológica ânsia humana de restaurar um paraíso perdido. 


\section{Referências}

ANDRESEN, S. M. B. Geografia. Lisboa: Edições Ática, 1967.

ANDRESEN, S. M. B. Obra poética. Lisboa: Caminho, 2010.

ANDRESEN, S. M. B. Sophia de Mello Breyner Andresen \& Jorge de Sena. Correspondência 1959-1997. Lisboa: Guerra e Paz, 2006.

CEIA, C. "Monólogo crítico" - Nos 50 anos de vida literária de Sophia de Mello Breyner Andresen. Colóquio/Letras, Lisboa, n. 132/133, p. 183-187, 1994.

COUTINHO, Isabel. Sophia foi recordada por poetas e amigos no final do Colóquio Internacional em sua honra. Público, Lisboa, 29. jan. 2011, p. 16.

EURÍPIDES. Ifigénia em Áulide. Coimbra: Festea - Temas Clássicos, 2008.

GUERREIRO, António. Entrevista a Sophia de Mello Breyner Andresen. Expresso, Lisboa, 15 jul. 1990, p. 54-57.

HOMERO. Ilíada. Lisboa: Livros Cotovia, 2005

HESÍODO. Teogonia Trabalhos e Dias. Lisboa: Imprensa Nacional-Casa da Moeda, 2005.

JAEGER, W. Paidéia. 3. ed. São Paulo: Martins Fontes, 1995.

MACHADO. J. P. Dicionário etimológico da língua portuguesa. 8. ed. Lisboa: Livros Horizonte, 2003.

MONTAIGNE, Michel. Os Ensaios. Da Experiência. São Paulo: Martins Editora, 2001. (Livro 3)

OVÍDIO. Les métamorphoses. 7. ed. Traduit par Georges Lafayet. Paris: Société D'Édition Les Belles Lettres, 1985. Tomo II, livro VII, p. 35-36, vs. 190-207.

TAVARES, F.S. Posfácio. In: TAVARES, Maria Andresen Sousa (Org.). Mar: Poesia de Sophia de Mello Breyner Andresen. Lisboa: Caminho, 2001. p. 167-175

TAVARES, M. S. Roma, Piazza Navona. Colóquio/Letras, Lisboa, n. 176, p. 127-129, 2011. 